\title{
Letter to Editor: Neuropsychiatric Consequences of Deep Brain Stimulation in Patients with Chronic Movement crosshark Disorders
}

ditation: Malakouti, S. K., Mahdavi, S. R., Naji, B., Asadi, M., \& Kahani, Sh. (2016). Neuropsychiatric consequences of deep brain stimulation in patients with chronic movement disorders. Basic and Clinical Neuroscience, 7(3), 185-186. http://dx.doi.org/10.15412/J.BCN.03070302

: http://dx.doi.org/10.15412/J.BCN.03070302

Nowadays, the main surgical treatment for Parkinson disease (PD) and other chronic movement disorders is deep brain stimulation (DBS), which has been reported to have consequences such as decline in verbal fluency and episodes of depression.

We designed an interventional study in 12 patients ( 9 men, 3 women) affected by PD, dystonia, and tic who underwent bilateral subthalamic nucleus (STN) DBS operation. We assessed each patient before surgery, 1 month, and then 1 year after the operation.

The results of our study showed a significant improvement with respect to the scores of the Short Form Health Survey (SF36). The Hamilton anxiety scale also showed an overall but insignificant improvement. The mean scores of the Beck depression inventory had a great drop 1 month after operation but a rise 12 months later, through an overall insignificant pattern.

Pearson correlation test showed a significant negative correlation between age and the changes of the SF36 scores. The BDI scores were assessed in relation with age. Although there was no actual relation between them before the operation, we detected a positive correlation between them 1 year after the DBS.

The results of our study were generally compatible with the results of Drapier et al. (2006), Heo et al. (2008), York et al. (2009), Paek et al. (2013), and amazingly similar to the meta-analysis published by Couti (2014) reporting an improvement in the mood of patients postoperatively that declines gradually with time. Is it possible to conclude that these changes are related with the differences between preoperative expectations and real long-term outcomes? Correlations between changes seen in BDI and SF36 scores with age can be considered as a confirmatory evidence for this argument. All cases showed an insignificant gradual decline in digit span test, which may be independent of the operation, according to the studyof York (2009). Although the Controlled Oral Word Association (COWA) test could not prove a significant deterioration in verbal fluency but a slight decline after 1 year was obvious, besides one patient who turned aphasic during this period. These results resemble the outcomes of the studies of Contarino et al. (2007) and York et al. (2009).

The outcomes showed that the benefits of DBS outweighs the slight risk of developing depression; However, patients especially the elderly must be under regular monitoring for early detection of mood changes. Adverse effect on verbal fluency is another important issue to be considered while evaluating the cost benefits of the operation. Thus ethically patients should be made aware of this potential risk before decision making.

According to negative correlation between the improvement in the quality of life and age, and the significant relationship between age and higher BDI scores, we strongly suggest that age be considered as a determinant factor in case selection.

\section{Acknowledgments}

We should thank Dr Mansour Parvaresh-Rizi for the performance of operations and also Dr Gholam Ali Shahidi for the tuning of the devices after the operation.

Seyed Kazem Malakouti', Seyed Reza Mahdavi', Borzooyeh Naji ${ }^{1 *}$, Mina Asadi ${ }^{1}$, Shamsoddin Kahani ${ }^{2}$

1. Tehran Psychiatric Institute, School of Behavioral Sciences and Mental Health, Iran University of Medical Sciences, Tehran, Iran.

2. Department of Psychiatry, Rasoul Akram Hospital, Iran University of Medical Sciences, Tehran, Iran.

* Corresponding Author:

Borzooyeh Naji, MD

Address: School of Behavioral Sciences and Mental Health, Iran University of Medical Sciences, Tehran, Iran.

Tel: +98 (21) 66550200

E-mail:naji.b@iums.ac.ir 


\section{References}

Contarino, M. F., Daniele, A., Sibilia, A. H., Romito, L. M., Bentivoglio, A. R., Gainotti, G., et al. (2007). Cognitive outcome 5 years after bilateral chronic stimulation of subthalamic nucleus in patients with Parkinson's disease. Journal of Neurology, Neurosurgery \& Psychiatry, 78(3), 248-252.

Drapier, D., Drapier, S., Sauleau, P., Haegelen, C., Raoul, S., Biseul, I., et al. (2006). Does subthalamic nucleus stimulation induce apathy in Parkinson's disease? Journal of Neurology, 253(8), 1083-1091.

Heo, J. H., Lee, K. M., Paek, S. H., Kim, M. J., Lee, J. Y., Kim, J. Y., et al. (2008). The effects of bilateral subthalamic nucleus deep brain stimulation (STN DBS) on cognition in Parkinson disease. Journal of the Neurological Sciences, 273(1), 19-24.

Paek, S. H., Yun, J. Y., Song, S. W., Kim, I. K., Hwang, J. H., Kim, J. W., et al. (2013). The clinical impact of precise electrode positioning in STN DBS on three-year outcomes. Journal of the Neurological Sciences, 327(1), 25-31.

York, M. K., Wilde, E. A., Simpson, R., \& Jankovic, J. (2009). Relationship between neuropsychological outcome and DBS surgical trajectory and electrode location. Journal of the Neurological Sciences, 287(1), 159-171. 